\title{
Functional Characterization of Acinetobacter baumannii Lacking the RNA Chaperone Hfq
}

\author{
Han-Yueh Kuo ${ }^{1,2}$, Hsuan-Hao Chao ${ }^{3}$, Po-Cheng Liao ${ }^{4}$, Long Hsu ${ }^{3}$, Kai-Chih Chang ${ }^{5}$, \\ Chi-Hua Tung ${ }^{6}$, Chang-Hua Chen ${ }^{7,8}$ and Ming-Li Liou ${ }^{4 *}$
}

\begin{abstract}
${ }^{1}$ Department of Medicine, National Taiwan University Hospital Hsin-Chu Branch, Hsinchu, Taiwan, ${ }^{2}$ Department of Internal Medicine, College of Medicine, National Taiwan University, Taipei, Taiwan, ${ }^{3}$ Department of Electrophysics, National Chiao Tung University, Hsinchu, Taiwan, ${ }^{4}$ Department of Medical Laboratory Science and Biotechnology, Yuanpei University, Hsinchu, Taiwan, ${ }^{5}$ Department of Laboratory Medicine and Biotechnology, Tzu Chi University, Hualien, Taiwan, ${ }^{6}$ Department of Bioinformatics, Chung Hua University, Hsinchu, Taiwan, ${ }^{7}$ Division of Infectious Disease, Department of Internal Medicine, Changhua Christian Hospital, Changhua, Taiwan, ${ }^{8}$ Center of Infection Prevention and Control, Changhua Christian Hospital, Changhua, Taiwan
\end{abstract}

\section{OPEN ACCESS}

Edited by:

David Wareham,

Queen Mary University of London, United Kingdom

Reviewed by: Gregory T. Robertson, Colorado State University,

United States

Karl M. Thompson,

Howard University, United States

${ }^{*}$ Correspondence:

Ming-Li Liou

d918229@gmail.com

Specialty section: This article was submitted to

Infectious Diseases,

a section of the journal

Frontiers in Microbiology

Received: 01 August 2017 Accepted: 09 October 2017 Published: 27 October 2017

Citation: Kuo H-Y, Chao H-H, Liao P-C, Hsu L, Chang K-C, Tung C-H, Chen C-H and Liou M-L (2017)

Functional Characterization of Acinetobacter baumannii Lacking the RNA Chaperone Hfa.

Front. Microbiol. 8:2068.

doi: 10.3389/fmicb.2017.02068
The RNA chaperone $\mathrm{Hfq}$ is involved in the riboregulation of diverse genes via small RNAs. Recent studies have demonstrated that $\mathrm{Hfq}$ contributes to the stress response and the virulence of several pathogens, and the roles of Hfq vary among bacterial species. Here, we attempted to elucidate the role of Hfq in Acinetobacter baumannii ATCC 17978. In the absence of $h f q$, A. baumannii exhibited retarded cell growth and was highly sensitive to environmental stress, including osmotic and oxidative pressure, $\mathrm{pH}$, and temperature. Compared to the wild-type, the Hfa mutant had reduced outer membrane vesicles secretion and fimbriae production as visualized by atomic force microscopy. The absence of $h f q$ reduced biofilm formation, airway epithelial cell adhesion and invasion, and survival in macrophage. Further, the hfq mutant induced significantly higher IL-8 levels in airway epithelial cells, which would promote bacterial clearance by the host. In addition to results similar to those reported for other bacteria, our findings demonstrate that $\mathrm{Hfq}$ is required in the regulation of the ironacquisition system via downregulating the bau $A$ and bas $D$ genes, the stress-related outer membrane proteins carO, A1S_0820, ompA, and n/pE, and the stress-related cytosolic proteins uspA and groEL. Our data indicate that Hfa plays a critical role in environmental adaptation and virulence in $A$. baumannii by modulating stress responses, surface architectures, and virulence factors. This study is the first to illustrate the functional role of $\mathrm{Hfq}$ in $\mathrm{A}$. baumannii.

Keywords: Acinetobacter baumannii, Hfq, adhesion, invasion, outer membrane vesicles

\section{INTRODUCTION}

Acinetobacter baumannii has emerged recently as a major cause of healthcare-associated infections worldwide (Maragakis and Perl, 2008). These organisms have been implicated in a diverse range of infections in hospitalized patients, especially patients with prolonged stays in intensive care units (Consales et al., 2011). The widespread capability of this organism may depend on the expression of virulence factors that enable bacterial infection and the expression of antimicrobialresistance determinants (Giamarellou et al., 2008; Gordon and Wareham, 2010). Several studies 
have investigated the mechanisms of pathogenicity and antimicrobial resistance contributing to the astonishing success of this pathogen. The remarkable resistance phenotype may be facilitated by the ability of A. baumannii strains, particularly those isolated from catheter-related urinary or bloodstream infections, to form biofilms that adhere to and persist on abiotic surfaces (Lee et al., 2008). The ability of A. baumannii to adhere to a number of epithelial cell lines has recently been investigated (Lee et al., 2006; Giannouli et al., 2013). Following adhesion, A. baumannii is able to invade and promote apoptosis of eukaryotic cells via OmpA (Omp36), which is trafficked to both the mitochondria and the nucleus and induces eukaryotic cell death pathways (Choi et al., 2008). The ability of $A$. baumannii to obtain and utilize resources such as iron via the siderophore acinetobactin is an another factor in survival both in the host and in the environment (Zimbler et al., 2009). Although a number of novel genes in A. baumannii with significant roles in pathogenesis have been discovered (Smith et al., 2007; Vallenet et al., 2008), the intrinsic regulatory mechanisms involved in environmental adaptation and disease progression remain unclear.

Post-transcriptional regulation of gene expression based on small non-coding RNA molecules (sRNAs), which is usually involved in the response to environmental stress to maintain cell homeostasis, has become a focus of interest in bacteria (Storz et al., 2011). sRNAs are usually 50-300 nucleotides long and modulate mRNA translation and/or stability by complementary base-pairing (Waters and Storz, 2009). One key player for many sRNA-mRNA interactions is the RNA chaperone Hfq (Vogel and Luisi, 2011). The Hfq protein, which belongs to the eukaryotic family of Sm proteins, was first discovered in Escherichia coli as a host bacterial factor required for RNA synthesis of bacteriophage Q $\beta$ (Franze de Fernandez et al., 1968). Hfq oligomerizes into a hexameric ring structure (Sauter et al., 2003) that facilitates sRNA-mRNA interactions and contributes to RNA regulation by interacting with the RNA turnover enzymes RNase E, polynucleotide phosphorylase, and poly(A) polymerase (Vogel and Luisi, 2011). Hfq is now regarded as a transcriptional regulator involved in stress responses, iron homeostasis, and outer membrane biogenesis (Chao and Vogel, 2010).

The influence of Hfq on physiology and virulence has been studied in a number of Gram-positive and Gram-negative bacteria (Sittka et al., 2007; Simonsen et al., 2011; Wang et al., 2014). Using $h f q$ null mutants and $h f q$ complementation strains, it has become clear that Hfq generally modulates motility and promotes resistance to cellular stresses such as oxidative stress or low pH (Chao and Vogel, 2010), but $h f q$ mutation results in diverse phenotypic changes in several bacterial species (Bohn et al., 2007; Sittka et al., 2007). Cellular genes involved in protection from nutrient deprivation, oxidative, and alcoholic stresses have been demonstrated in A. baumannii (Fiester and Actis, 2013). For example, several genes involved in the acinetobactin-mediated iron acquisition system, such as bas, bau, and bar, play roles in the ability of A. baumannii to cause infections in hosts that impose iron-limiting stress (Gaddy et al., 2012). In addition, genes involved in protection from oxidative stressors such as the universal stress protein A (uspA) (Elhosseiny et al., 2015), nlpE (Dorel et al., 2006), A1S_0820 (Buist et al., 2008), carO (Mussi et al., 2007), groEL (Soares et al., 2010), and ompA (Soares et al., 2010) have been identified. Although Hfq plays critical roles in the resistance to cellular stresses, the correlation between $\mathrm{Hfq}$ and these stress-related molecules in A. baumannii remains unclear.

The role of Hfq in A. baumannii is not known. The aim of this study was to clarify the function of the Hfq homolog of A. baumannii in virulence and stress responses. We constructed a $h \mathrm{fq}^{-}$mutant of the A. baumannii 17978 type strain by gene replacement and a $h f q$-complemented strain. We demonstrated that loss of $h f q$ affects a number of virulence-associated phenotypes, including bacterial morphology, biofilm formation, resistance to stress response, cell adhesion, and invasion ability, in A. baumannii ATCC17978. In addition, we demonstrated that loss of $h f q$ affects transcription of genes involved in stress response. This is the first report of the functional roles of A. baumannii Hfq.

\section{MATERIALS AND METHODS}

\section{Bacterial Strains, Plasmids, and Primers}

The bacterial strains and plasmids used in this study are listed in Table 1. The primers used in this study are listed in Supplementary Table S1. Bacteria were routinely cultured at $37^{\circ} \mathrm{C}$ in Mueller-Hinton $(\mathrm{MH})$ medium at $37^{\circ} \mathrm{C}$ with constant shaking unless otherwise indicated.

\section{Replacement of the A. baumannii hfq Gene}

The whole genome sequence of A. baumannii ATCC17978 was obtained from GenBank (Smith et al., 2007) and adopted to manipulate the A. baumannii ATCC 17978 genome. The

TABLE 1 | Bacterial strains and plasmids used in this study.

\begin{tabular}{|c|c|c|}
\hline Strain or plasmid & $\begin{array}{l}\text { Genotype and/or } \\
\text { characteristics }\end{array}$ & $\begin{array}{l}\text { Reference or } \\
\text { source }\end{array}$ \\
\hline \multicolumn{3}{|c|}{ A. baumannii strains } \\
\hline ATCC 17978 & Wild-type strain & ATCC $^{a}$ \\
\hline$\Delta \mathrm{hfq}$ & $\Delta h f q$ & This study \\
\hline Hfqc & $\Delta h f q$ harboring $\mathrm{pHFQ}$ & This study \\
\hline \multicolumn{3}{|l|}{ E. coli } \\
\hline $\mathrm{DH} 5 \alpha$ & $\begin{array}{l}\text { Used for recombinant } \\
\text { DNA methods }\end{array}$ & Invitrogen \\
\hline \multicolumn{3}{|l|}{ Plasmid } \\
\hline pWH1266_km & $\begin{array}{l}\text { Amp }^{r} \mathrm{Tc}^{r} \mathrm{Km}^{r} \\
\text { expression vector }\end{array}$ & Zimbler et al., 2009 \\
\hline pGEM-T & $\begin{array}{l}\text { High-copy-number } \\
\text { cloning vector; Ampr }\end{array}$ & $\begin{array}{l}\text { GMBiolab, } \\
\text { Taichung, Taiwan }\end{array}$ \\
\hline pHFQ & $\begin{array}{l}\text { pWH1266_km } \\
\text { harboring the } 17978 \\
\text { hfq allele }\end{array}$ & This study \\
\hline
\end{tabular}

aAmerican Type Culture Collection (Manassas, VA, United States). ' ${ }^{\mathrm{A}} \mathrm{Amp}$ ', ampicillin resistance; $\mathrm{TC}^{r}$, tetracycline resistance; $\mathrm{Km}^{r}$, kanamycin resistance. 
hfq::Km mutants were constructed by a previously described method (Aranda et al., 2010). Briefly, polymerase chain reaction (PCR) was used to amplify regions of the sequences upstream and downstream of the $h f q$ gene using the primer pairs (Supplementary Table S1) Up_Hfq_F and Hfq_kan_R to amplify the 311-bp region upstream of the $h f q$ gene and Kan_Hfq_F and Dw_Hfq_R to amplify the 220-bp region downstream of the $h f q$ gene. The primers Hfq_kan_R and Kan_Hfq_F have approximately 22 nucleotides of overlapping sequence, resulting in fusion of the hfq upstream and downstream sequences with the kanamycin resistance gene after fusion PCR. The 311 and 220-bp DNA fragments containing the overlapping sequences from the $\mathrm{km}$ gene were fused together by PCR with a complementary $\mathrm{km}$ PCR fragment, resulting in the replacement of $h f q$ with $\mathrm{km}$. The resulting PCR product was gel purified using a gel extraction kit (Favorgen, PIF, Taiwan). The fused PCR fragment was electroporated into wild-type A. baumannii ATCC 17978. The $\Delta \mathrm{hfq}$ strains were identified by screening transformants on LB agar plates containing kanamycin $(50 \mu \mathrm{g} / \mu \mathrm{l})$. The deletion mutant was confirmed using conventional PCR for diagnostic size shifts by gel electrophoresis and was further confirmed by real-time reverse transcription PCR (RT-PCR).

\section{Complementation Study}

The $h f q$ parental allele was PCR amplified using the primers hfq_Expr_XhoI_F and hfq_Expr_XbaI_R and ligated into the A. baumannii-E. coli shuttle vector pWH1266_km (Lin et al., 2014). The recombinant DNA products were verified by sequencing. The resulting plasmid pHFQ was used to transform the $\Delta \mathrm{hfq}$ strain by electroporation with selection by tetracycline. The expression of the $h f q$ gene in the $\Delta$ hfq mutant and its complementation clone $\Delta \mathrm{hfqc}$ was verified using real-time RT-PCR by the method previously described (Chang et al., 2014). The relative expression level of $h f q$ was normalized using that of 16 s rRNA.

\section{Atomic Force Microscopy (AFM)}

Overnight bacterial cultures were diluted 1:100 and subcultured for $3 \mathrm{~h}$. The bacteria were recovered by centrifugation at $3,000 \mathrm{~g}$ for $10 \mathrm{~min}$, washed with deionized water, and suspended in deionized water at an $\mathrm{OD}_{600}$ of 0.07 . Droplets of each sample were deposited on glass slides for $10 \mathrm{~min}$. Then, the droplets were removed, and the slides were dried for $20 \mathrm{~min}$ to immobilize the cells. The morphology of the bacteria was analyzed by atomic force microscopy (AFM; Dimension Icon, Bruker, Billerica, MA, United States) using an SNL-W-D triangular cantilever probe (Bruker) with a nominal $0.06 \mathrm{~N} / \mathrm{m}$ spring constant and 2-nm tip curvature radius. Measurements were obtained in peak force tapping mode (or Quantitative NanoMechanics mode, QNM mode). The images obtained were analyzed using NanoScope Analysis 1.4 software (Bruker). The AFM scanning sizes were $3 \mu \mathrm{m} \times 3 \mu \mathrm{m}$ with scan rates of $1 \mathrm{~Hz}$. The spatial resolution of image is $5.86 \mathrm{~nm} /$ pixel. For each measurement, height sensor and peak force error images were recorded simultaneously. The height sensor image specifies fimbria morphology, while the peak force error image emphasizes edges of bacterial structures.

\section{Isolation of $A$. baumannii OMVs}

Outer membrane vesicles (OMVs) are isolated using the method of Rosen et al. (1995). Protein concentrations were determined and then equal volume of OMV content in each strain was analyzed by $10 \%$ SDS-PAGE.

\section{Growth Curves}

A. baumannii strain ATCC17978 (wild-type) and the $\Delta$ hfq and $\Delta$ hfqc strains were cultured overnight in $\mathrm{MH}$ medium at $37^{\circ} \mathrm{C}$, and the overnight culture was subcultured at 1:100 in $100 \mathrm{ml}$ of $\mathrm{MH}$ medium. The cultures were incubated with shaking at $200 \mathrm{rpm}$ in $250-\mathrm{ml} \mathrm{Scott} \mathrm{flasks} \mathrm{at} 37^{\circ} \mathrm{C}$ for $22 \mathrm{~h}$. Every hour, the optical density was measured at $600 \mathrm{~nm}\left(\mathrm{OD}_{600}\right)$.

\section{Stress Tolerance Assays}

For the stress tolerance test, overnight cultures were diluted to an $\mathrm{OD}_{600}$ of 0.01 with $\mathrm{MH}$ broth. For temperature effects, cells were cultured at 20 and $50^{\circ} \mathrm{C}$, respectively. For high osmolarity and oxidative stress effects, $\mathrm{NaCl}$ and $\mathrm{H}_{2} \mathrm{O}_{2}$ were added to the bacterial cell suspension at concentrations of $3 \%$ and $20 \mathrm{mM}$, respectively. In addition, ethanol and Triton X-100 were added to the bacterial suspension at concentrations of 3 and $1 \%$, respectively. For acid and alkaline stress conditions, cells were cultured at $\mathrm{pH} 5.5$ and $\mathrm{pH}$ 8.5, respectively. Bacterial growth with or without external stress was monitored by measuring the $\mathrm{OD}_{600}$. After treatment with $\mathrm{H}_{2} \mathrm{O}_{2}$ for $30 \mathrm{~min}$, the cells were diluted and plated on LB plates to determine the number of colony forming units (CFUs). The results represent the mean of at least three separate experiments.

\section{Evaluation of Stress-Related Gene Expression by Real-Time RT-PCR}

To study the effect of the $h f q$ mutation on the mRNA levels of basD, bauA, uspA, nlpE, A1S_0820, carO, groEL, and ompA, overnight cultures of the wild-type, $\Delta \mathrm{hfq}$, and $\Delta \mathrm{hfqc}$ strains were washed, and total RNA was isolated for real-time RT-PCR.

\section{Biofilm Assays and Evaluation of Fimbria Expression by Real-Time PCR (qPCR)}

Biofilm formation on polystyrene tubes was assessed by crystal violet staining of cells cultured in LB broth as previously described. The expression of the $c s u A / B$ gene (A1S_2218) and fim-like adhesion gene (A1S_1507) in the $\Delta \mathrm{hfq}$ mutant and its complementation clone $\Delta \mathrm{hfqc}$ was verified using real-time RT-PCR by the method previously described (Chang et al., 2014). The relative expression levels of A1S_2218 and A1S_1507 were normalized by that of $16 \mathrm{~s}$ rRNA.

\section{Intra-Macrophage Survival Assay}

The assay was performed as described with some modifications (Wang et al., 2014). Briefly, mouse macrophage cells (RAW264.7) were cultured to $1 \times 10^{6}$ cells/well in 24 -well plates in RPMI 1640 medium. The overnight culture of $A$. baumannii was applied to each well at an MOI of 10 . Bacteria were co-incubated with macrophages for $120 \mathrm{~min}$ at $37^{\circ} \mathrm{C}$. After infection, the cells were washed and incubated for $1 \mathrm{~h}$ with streptomycin $(250 \mu \mathrm{g} / \mathrm{ml})$ 
containing medium. The CFU obtained from the lysate of the wild-type-infected macrophages was set as $100 \%$, and other data were relative to this value.

\section{Cell Adhesion and Invasion Assays}

Cell adhesion and invasion assays were performed as described with some modification (Wang et al., 2014). A549 (Human lung carcinoma cell line, epithelial cell; BCRC 60074) and NCI-H292 (human mucoepidermoid pulmonary carcinoma cell line, endothelial cell; BCRC 60372) were purchased from Food Industry Research and Development Institute, Hsinchu, Taiwan. Briefly, overnight bacterial cultures were diluted 100-fold and grown for 2 h. A549 cells and NCI-H292 cells were infected at $37^{\circ} \mathrm{C}$ for $2 \mathrm{~h}$ with bacterial suspensions at a multiplicity of infection (MOI) of 10. For the adhesion assay, infected monolayers were washed with PBS to remove non-adherent bacteria and lysed with $1 \%$ Triton X-100. The cell lysates were plated on LB agar plates to determine the total CFU associated with the cells. For the invasion assay, the infected cells were washed and further incubated at $37^{\circ} \mathrm{C}$ for $2 \mathrm{~h}$ in RPMI 1640 medium containing streptomycin $(500 \mu \mathrm{g} / \mathrm{ml})$ to kill extracellular bacteria. Cells were lysed and plated on LB agar to quantify viable invading bacteria. The adhesion ability was expressed as the percentage of adherent bacteria versus the total inoculum, and the invasion ability was expressed as the percentage of viable bacteria that survived the streptomycin treatment versus the total inoculum.

\section{Cytokine Evaluation by Real-Time RT-PCR}

Overnight bacterial cultures were diluted 100-fold and grown for 2 h. A549 cells and $\mathrm{H} 292$ cells were infected at $37^{\circ} \mathrm{C}$ for $1 \mathrm{~h}$ at an MOI of 10. The infected cells were collected, and total RNA was isolated using an RNeasy minikit (Qiagen). The mRNA expression of IL-8 and IL-6 in A549 cells and H292 cells was determined by real-time RT-PCR as described (Kim et al., 2015). The relative amounts of cytokines in each infected cell line were normalized to the expression levels of the GAPDH gene.

\section{Statistical Analysis}

The means of group differences were determined using a one-way ANOVA. A $p$-value $<0.05$ was considered statistically significant. Data entry and analyses were performed using the Statistical Package for the Social Sciences software version 21.0 (SPSS Inc., Chicago, IL, United States).

\section{RESULTS}

\section{Construction of the A. baumannii hfq Mutant}

Several studies have demonstrated that Hfq participates in the pathogenesis of many bacteria via different mechanisms. Here, we studied the effects of an Hfq-like protein on the pathogenesis of A. baumannii ATCC 17978. The gene (A1S_3785) homolog of the $h f q$ gene, which is predicted to encode a protein of 168 amino acids, is located at 2,465,843-2,466,349 bp in the genome of A. baumannii ATCC17978 (Eijkelkamp et al., 2011). This gene (A1S_3785) and its encoded protein are almost twice the size of other gammaproteobacterial Hfqs due to an elongated C-terminus (Supplementary Figure S1). The N-terminal domains of Hfq in most bacteria are highly conserved between amino acid residues 1 and 66 (Supplementary Figure S1), a region that is responsible for RNA-binding and protein-protein interactions among Sm [the core of small nuclear ribonucleoprotein particles (snRNPs)] and Sm-like proteins (Moller et al., 2002). By contrast, the C-terminal end of $A$. baumannii $\mathrm{Hfq}$ contains a glycinerich domain with a repetitive pattern, which was similar to the A. baylyi $h f q$ gene encoding a usual C-terminus (Schilling and Gerischer, 2009). Compared to the Hfq protein lengths in several bacteria, the largest known Hfq proteins are annotated in members of the gammaproteobacterial family Moraxellaceae (Supplementary Table S1). The annotated Hfq lengths are between 168 and 174 amino acids for Acinetobacter and up to 210 amino acids for M. catarrhalis. Although Hfq shows a strong variation in its C-terminus (Vecerek et al., 2008), this C-terminus of $\mathrm{Hfq}$ in A. baylyi was not responsible for growth and cell phenotype (Schilling and Gerischer, 2009). To examine the role of $\mathrm{Hfq}$ in $A$. baumannii, we generated an isogenic mutant by the replacing the conserved $h f q$ sequence with the kanamycin resistance gene $(\Delta \mathrm{hfq})$ and an Hfq-complemented strain $(\Delta \mathrm{hfqc})$, as shown in Figure 1A. The loss of $h f q$ was verified by PCR and sequencing (Figure 1B). The loss and recovery of $h f q$ expression was confirmed in the $\Delta h f q$ and $\Delta h f q c$ strains by real-time RT-PCR (Figure 1C).

\section{Visualization of Cell Morphology}

The cell morphologies of the three A. baumannii strains (WT, $\Delta \mathrm{hfq}$, and $\Delta \mathrm{hfqc}$ ) were visualized from the AFM peak force error images, as shown in Figure 2A. $\Delta$ hfq expressed very few fimbriae (white arrow), compared to WT and $\Delta$ hfqc strains. Figure 2B shows the comparison of the cell sizes by estimating the bacterial spreading areas from the AFM height sensor images as shown in Figure 2A. The cell area (A) and number ( $n$ ) are as following: WT (A: $1.82 \pm 0.27 \mu \mathrm{m}^{2}, n$ : 5) and $\Delta$ hfqc (A: $\left.2.03 \pm 0.57 \mu \mathrm{m}^{2}, n: 5\right)$ strains were both significantly larger than $\Delta$ hfq $\left(\mathrm{A}: 0.98 \pm 0.17 \mu \mathrm{m}^{2}, n: 6\right)(p<0.01)$. This result reveals that a lack of $h f q$ could restrain the growth of A. baumannii. There was no significant size difference between WT and $\Delta$ hfqc. OMVs (dashed white circle) were dominant in wild-type and were greatly reduced in the $\Delta \mathrm{hfq}$ strain.

To verify that $\Delta \mathrm{hfq}$ strain reduced OMVs secretion, the quantitative assay of OMVs was performed and the result was shown in Figure 2C. The total protein content of OMVs was largely reduced in $\Delta \mathrm{hfq}$ strain compared to WT and $\Delta \mathrm{hfqc}$ strains. Based on the study of Jin et al. (2011), OmpA of A. baumannii is the most abundant protein in OMVs with a molecular mass of $38 \mathrm{KDa}$. Taken together, the levels of OmpA were reduced in $\Delta \mathrm{hfq}$ strain compared to WT and $\Delta \mathrm{hfqc}$ strain.

\section{Growth Effects on hfq Deletion Mutants}

Growth defects resulting from the loss of $h f q$ have been demonstrated in several bacterial species (Sonnleitner et al., 2003; 

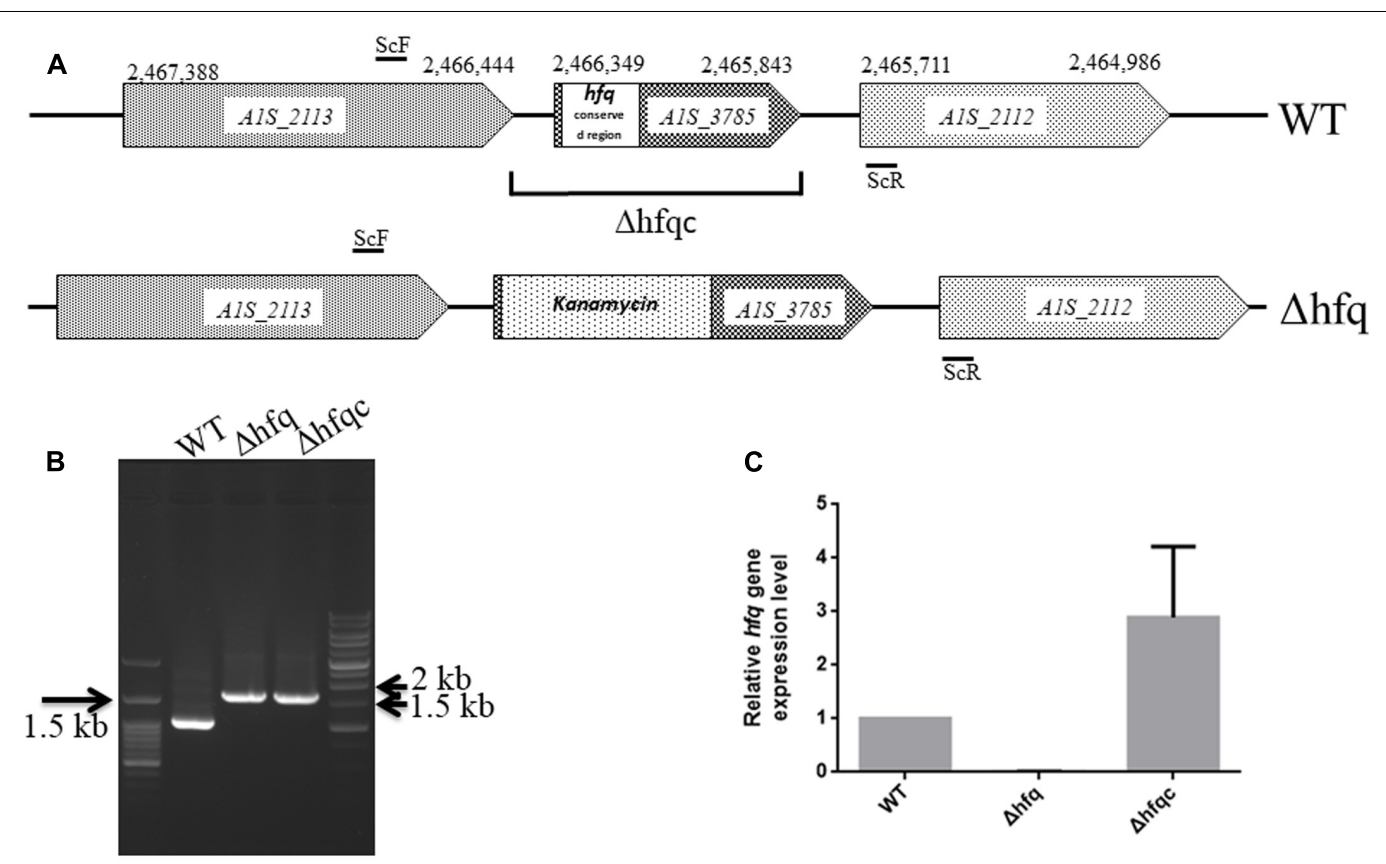

FIGURE 1 | Mutational analysis of the A. baumannii ATCC 17978 hfq gene. (A) Schematic representation of the linear DNA constructed for the $h f q$ gene replacement. The numbering denotes the gene coordinates in the $A$. baumannii genome database. In the $\Delta$ hfq mutant, the conserved region (1-66 amino acid) of the Hfq ORF was replaced by the kanamycin resistance gene. The DNA fragment cloned in the complementation plasmid in $\Delta$ hfac is indicated. The primers used are listed in Supplementary Table S1. (B) Screening of $h f q A$. baumannii mutants generated by gene replacement. WT, wild-type control with 994 bp. $\Delta$ hfq and $\Delta$ hfqc (from kanamycin replacement) with 1,636 bp. (C) Hfq mRNA expression analyzed by real-time RT-PCR.

Geng et al., 2009; Wang et al., 2014). To evaluate the growth effects in $h f q$ deletion mutants, we monitored the growth of the wild-type, $\Delta$ hfq mutant, and $\Delta$ hfqc strains in $\mathrm{MH}$ broth. The loss of $h f q$ resulted in growth retardation of $7 \mathrm{~h}$ (Figure 3). On $\mathrm{MH}$ agar plates, except for colony size, other colony characteristics such as form, elevation, and margin did not differ between $h f q$ mutant and wild-type strain (data not shown).

\section{The Effect of Hfq on Stress Tolerance}

Acinetobacter baumannii has gradually become a leading nosocomial pathogen worldwide. The widespread dissemination of $A$. baumannii in hospital environments indicates that this organism might tolerate environmental stresses. To determine if $\mathrm{Hfq}$ contributes to external stress tolerance, the growth of the WT, $\Delta \mathrm{hfq}$, and $\Delta \mathrm{hfqc}$ strains was assessed under various stress conditions. Hfq mutants showed defects in growth upon exposure to all stressors (Figure 4). The reduced tolerance of the Hfq mutant was restored to near wild-type levels by introduction of the Hfq-expressing plasmid. This result implies that $\mathrm{Hfq}$ contributes to the resistance to stresses such as temperature, $\mathrm{pH}$, osmotic pressure, and oxidative stress in A. baumannii.

\section{The Effect of Hfq on the mRNA Expression of Stress-Related Molecules}

As Hfq contributes to external stress tolerance, the effect of Hfq on the mRNA expression of the genes involved in stress tolerance, including the acinetobactin-mediated iron acquisition system such as bas and bau, and growth-related stresses such as uspA, nlpE, A1S_0820, carO, groEL, and ompA, was evaluated (Figure 5). Our result showed that the expression of all genes, including basD, bauA, uspA, nlpE, A1S_0820, carO, ompA, and groEL, was significantly higher in $\Delta \mathrm{hfq}(p<0.05)$ than in WT and was completely or partially restored in the $\Delta$ hfqc strain. These data indicate that $\mathrm{Hfq}$ is required to modulate the expression of stress-related genes to survive stress.

\section{The Effect of Hfq on Biofilm Formation and Fimbria Production, Adhesion, Invasion, and Cytokine Production in Lung Epithelial Cells}

Acinetobacter baumannii form biofilms, a phenotype that may explain its ability to survive in nosocomial environments and to cause device-related infections in compromised patients (Lee et al., 2008). As shown in Figure 6A, when $h f q$ was deleted, biofilm formation was somewhat decreased compared with wild-type. Fimbria assembly plays an important role in biofilm initiation and maturation after initial attachment to abiotic surfaces (Gaddy and Actis, 2009). Two types of fimbria, the CsuA/B-A-B-C-D-E chaperone-usher secretion system and fim-like type 1 fimbria (A1S-1507 to A1S_1510), have been reported in A. baumannii (Tomaras et al., 2003; Nait Chabane et al., 2014). CsuA/BABCDE-dependent fimbriae are involved in biofilm formation, whereas the function of fim-like fimbria remains unclear. To determine if $\mathrm{Hfq}$ plays a role in fimbriae 


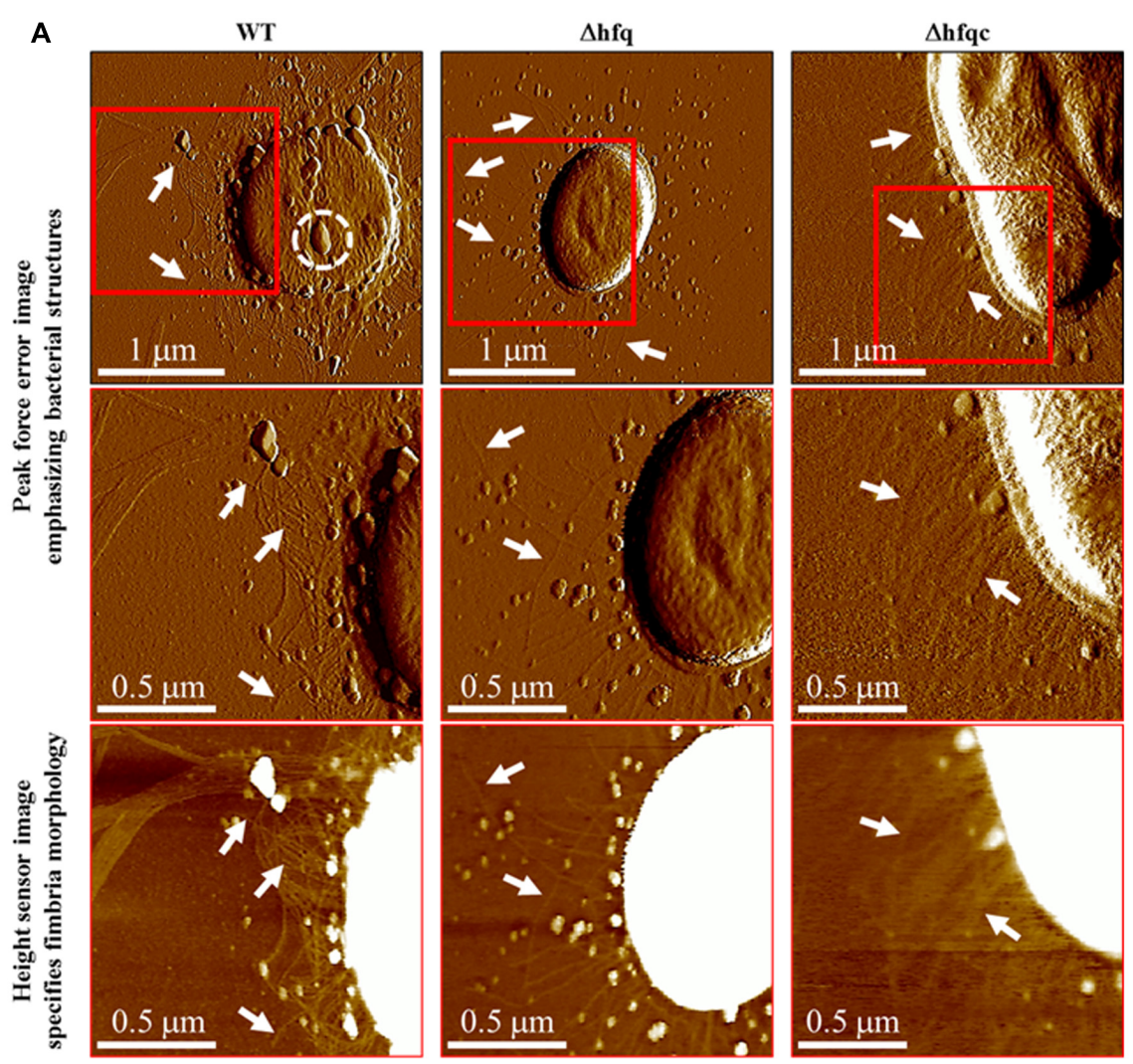

B

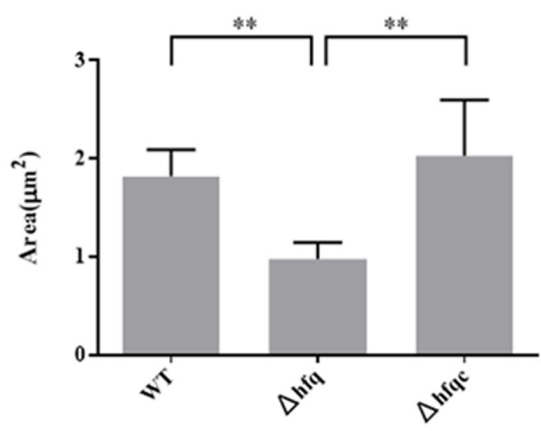

C

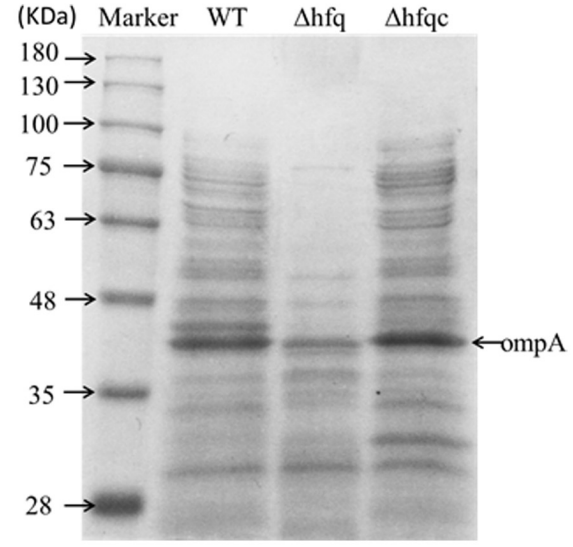

FIGURE 2 | Cell morphology visualization. (A) Cell morphology visualization by AFM. Columns from left to right are WT, $\Delta$ hfa, and $\Delta$ hfqc. The first row shows the peak force error images of the three strains. The second row and third row are the peak force error images and the height sensor images of the red square region of the first row, respectively. The white arrow indicates fimbriae while the dashed white circle indicates outer membrane vesicles (OMV). Numbers of cells analyzed for WT, $\Delta \mathrm{hfq}$, and $\Delta \mathrm{hfqc}$ are 6,13 , and 7 , respectively. (B) Inactivation of $\mathrm{Hfq}$ leads to decreased cell size. ${ }^{* *} p<0.01$. (C) Equal volume of total protein content of A. baumannii OMVs was subjected to $10 \%$ SDS-PAGE.

production, the expression levels of $\operatorname{csuA} / B$ and A1S_1507 in the wild-type and $\Delta \mathrm{hfq}$ and $\Delta \mathrm{hfqc}$ strains were examined by real-time RT-PCR as shown in Figure 6B. CsuA/B levels were significantly reduced $(p<0.01)$, whereas A1S_1507 levels were significantly increased $(p<0.01)$ in the $\Delta$ hfq strain compared with the wild-type and $\Delta$ hfqc strain, indicating that $\mathrm{Hfq}$ is required to modulate fimbriae production in different ways. 


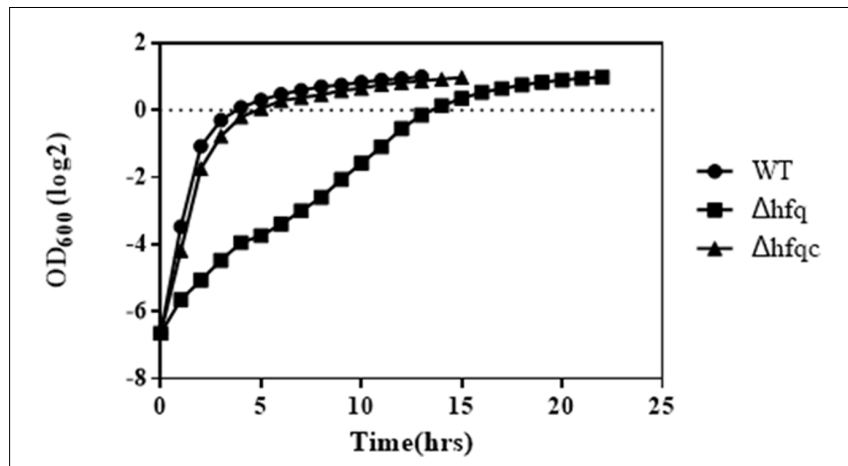

FIGURE 3 | Growth of $A$. baumannii $\Delta$ hfq in Mueller-Hinton medium. A. baumannii wild-type, $\Delta \mathrm{hfq}$ and $\Delta$ hfqc cells were cultured in $\mathrm{MH}$ broth at $37^{\circ} \mathrm{C}$. The OD600 values of each strain were measured hourly. The error bars represent the means and standard errors of the mean (SEM) of three independent replicates.

\section{Deletion of $h f q$ Affects the Adhesion, Invasion, and Cytokine Production of Airway Epithelial Cells}

Acinetobacter baumannii colonizes biotic surfaces by adherence and invasion to host cells to evade immune attacks and subsequent bacterial persistence (Lee et al., 2006). To test the role of Hfq in A. baumannii virulence, the ability of wild-type and $\Delta \mathrm{hfq}$ mutant cells to adhere to and invade A549 lung adenocarcinoma cells and NCI-H292 human bronchial epithelial cells was assessed. $\Delta \mathrm{hfq}$ exhibited impaired abilities to adhere to and invade A549 and NCI-H292 cells (Figures 7A,B). IL-8 and IL-6, which cause neutrophil infiltration and non-resolving inflammation, are key cytokines contributing to bacterial elimination by host cells and are expressed in the epithelial lining (Oglesby et al., 2015). IL-6 acts as both a pro-inflammatory cytokine and an anti-inflammatory myokine (Scheller et al., 2011), and IL-8 plays an important role in acute inflammation (Baggiolini and Clark-Lewis, 1992). Because Hfq plays a role in A. baumannii adherence and invasion of lung epithelial cells, we examined the production of IL- 8 and IL- 6 by A549 and NCI-H292 cells challenged with wild-type or $\Delta$ hfq mutants. As shown in Figure 7C, IL-8 expression was significantly increased $(p<0.001)$ in both cells upon exposure to $\Delta$ Hfq. However, IL-6 expression was significantly decreased $(p<0.01)$ in A549 cells but increased $(p<0.05)$ in NCI-H292 cells upon exposure to the $\Delta$ hfq mutant compared with the WT and $\Delta$ hfqc strains. This result implies that $h f q$ deletion may stimulate IL-8 in A549 and NCI-H292 cells. Moreover, the deletion of $h f q$ on IL-6 expression in both cells is different.

\section{Deletion of $h f q$ Increased Killing of A. baumannii by Macrophage Cells}

In order to understand if $\mathrm{Hfq}$ is involved in the innate ability of macrophage to eliminate $A$. baumannii, we co-cultured macrophages with bacteria, killed external
A

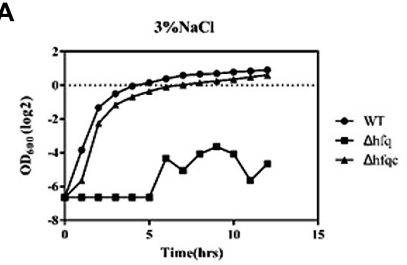

D

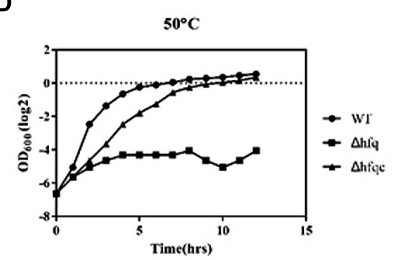

B

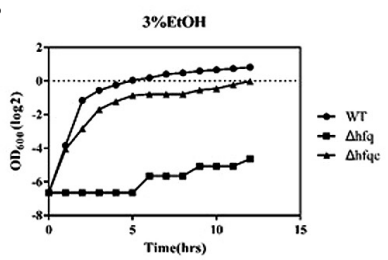

E

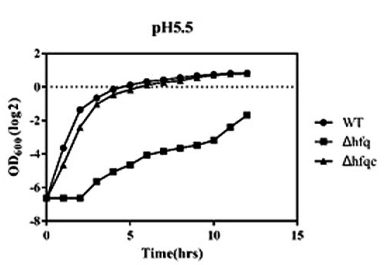

C
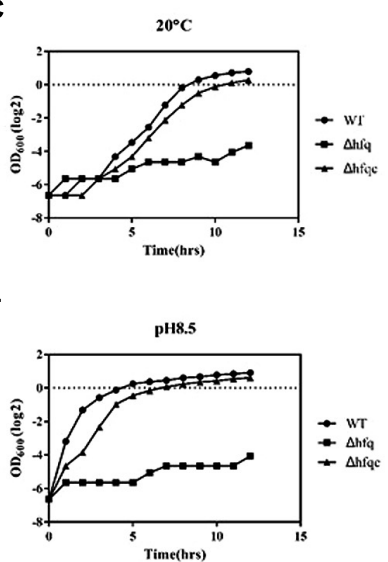

G

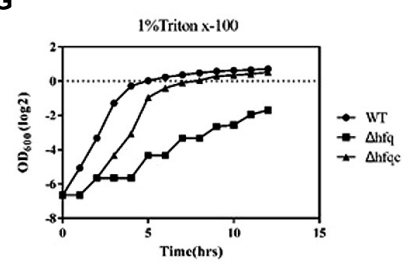

H

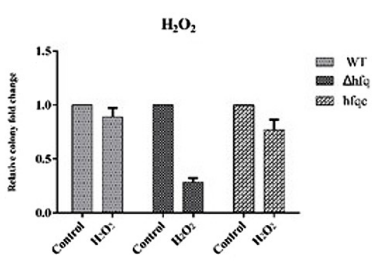

FIGURE 4 | The effect of Hfq on stress tolerance of $A$. baumannii. Tolerance to (A) $3 \% \mathrm{NaCl}$; (B) $3 \%$ ethanol; (C) $20^{\circ} \mathrm{C}$; (D) $50^{\circ} \mathrm{C}$; (E) $\mathrm{pH} 5.5 ;$ (F) pH $8.5 ;$ (G) $1 \%$ Triton X-100; (H) $20 \mathrm{mM} \mathrm{H}_{2} \mathrm{O}_{2}$. Bacterial cultures in exponential phase were adjusted to $10^{8} \mathrm{cells} / \mathrm{ml}$ with or without external stress. Bacterial growth was monitored by measuring the $\mathrm{OD}_{600}$. The numbers of bacteria surviving $\mathrm{H}_{2} \mathrm{O}_{2}$ stress were measured, and the relative cell survival was obtained relative to the untreated control. All data represent the average of three independent experiments with the SD. 


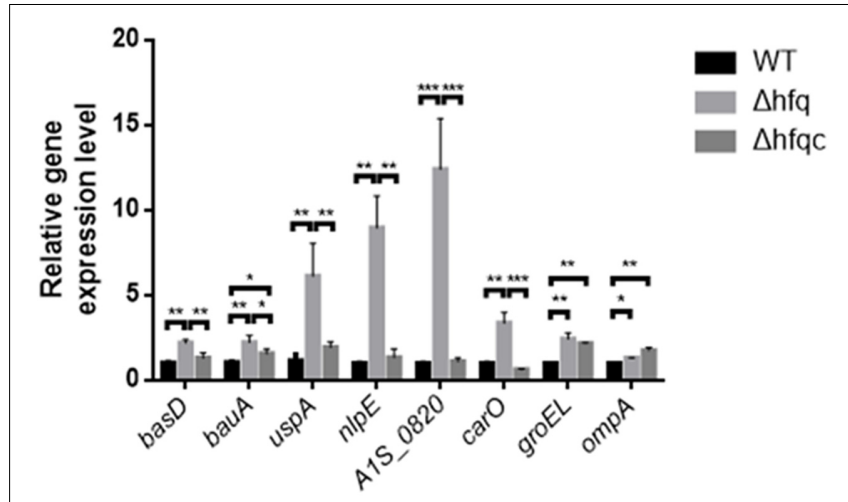

FIGURE 5 | The effect of Hfq on the expression of stress-related signaling molecules. The relative mRNA expression of the basD, bauA, uspA, n/pE, A1S_0820, carO, groEL, and ompA genes in the WT, $\triangle \mathrm{hfq}$, and $\triangle \mathrm{hfqc}$ strains was determined by real-time RT-PCR. All data represent the average of three independent experiments with the SD. ${ }^{*} p<0.05 ;{ }^{* *} p<0.01 ;{ }^{* *} p<0.001$.

bacteria with streptomycin, and assessed the survival of internalized A. baumannii after streptomycin treatment by lysing macrophage cells. As shown in Figure 7D, the relative survival of $h f q$ mutant was reduced to $0.1 \%$ at $2 \mathrm{~h}$ after streptomycin treatment. The Hfq-complemented strain was partially restored the survival pattern compared to the wild-type.

\section{DISCUSSION}

Wide adaptation in the hospital environment enables microorganisms such as A. baumannii to become public healthcare-associated issues (Tang et al., 2015). Many studies have demonstrated that Hfq is associated with the timely adaptation to the environment and virulence of several pathogens (Sonnleitner et al., 2003; Chao and Vogel, 2010; Wang et al., 2014). hfq mutants have variable phenotypes among different bacteria. For example, improvement of motility was noted in a Yersinia $h f q$ mutant (Schiano et al., 2010), but Salmonella, P. aeruginosa, and $E$. coli were impaired in motility upon loss of the $h f q$ gene (Sonnleitner et al., 2003; Sittka et al., 2007; Kulesus et al., 2008). In addition, loss of the $h f q$ gene decreases RpoS production in Salmonella and E. coli but not V. cholerae (Ding et al., 2004). These results show that the function of $\mathrm{Hfq}$ may be unique in each bacterial species. A previous study concerning about the hfq effect on A. baylyi showed that deletion of the complete $h f q$ open reading frame resulted in severe reduction of growth (Schilling and Gerischer, 2009), which is consistent with our result. Herein, we first described the characteristics of A. baumannii $\mathrm{Hfq}$ involved in environmental adaptation and virulence. The $h f q$ mutation led to pleiotropic phenotypic effects, including changes in stress tolerance, biofilm formation, cell morphology, epithelial cell adhesion and invasion, and survival in macrophage. The partial complementation in bauA, groeL, and ompA expression and cell adhesion, invasion, and intra-macrophage survival
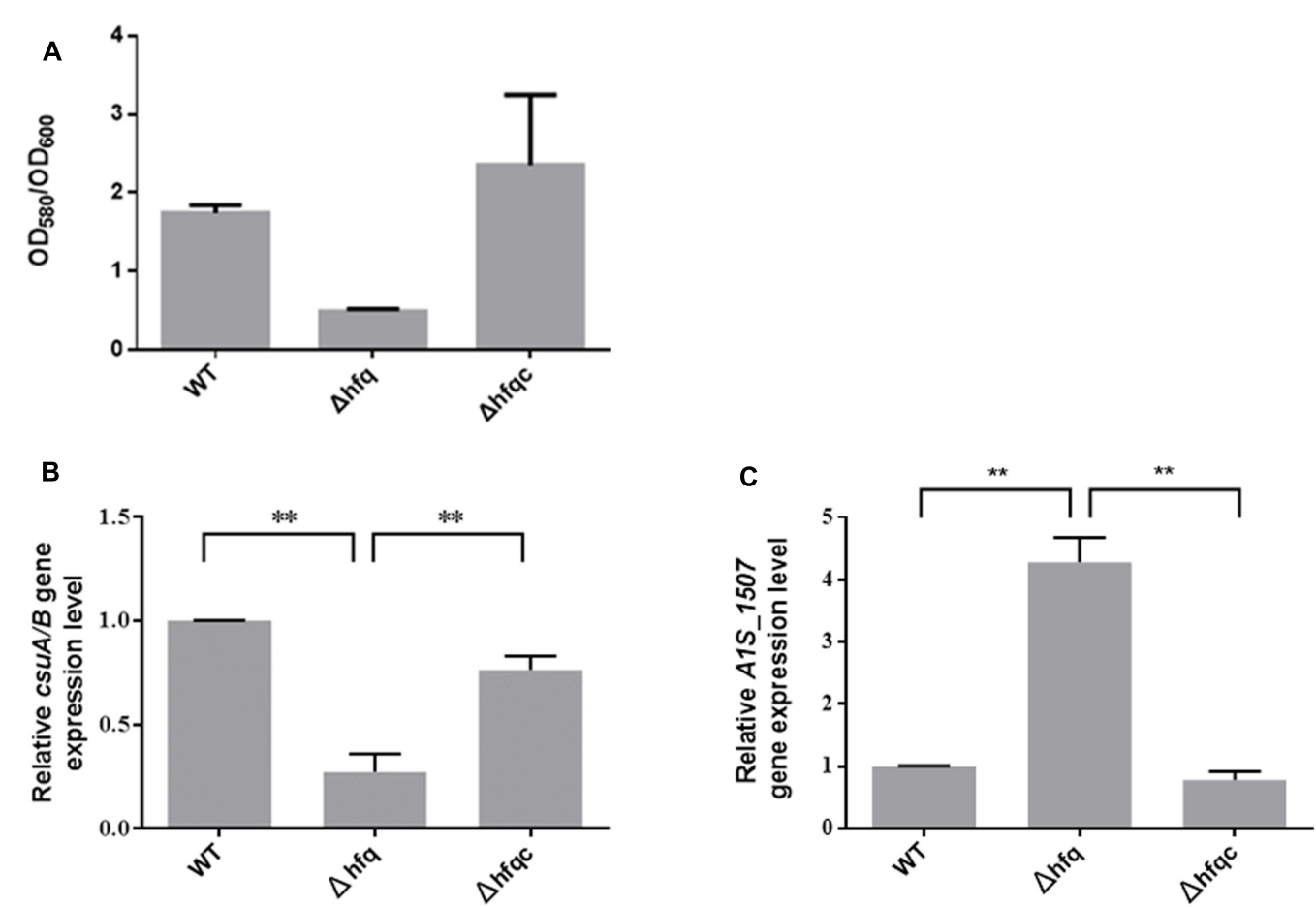

FIGURE 6 | The effect of Hfq on biofilm formation and fimbria expression. (A) Biofilm formation in the WT, $\Delta \mathrm{hfq}$, and $\Delta$ hfqc strains. The biofilm level was determined as described in the Section "Materials and Methods." (B) Three dimension features of bacterial biofilm structure visualized by scanning electron microscopy. (C) Relative mRNA expression of $c s u A / B$ and A1S_1507 was analyzed using real-time RT-PCR. All data represent the average of three independent experiments with the SD. ${ }^{* *} p<0.01$. 

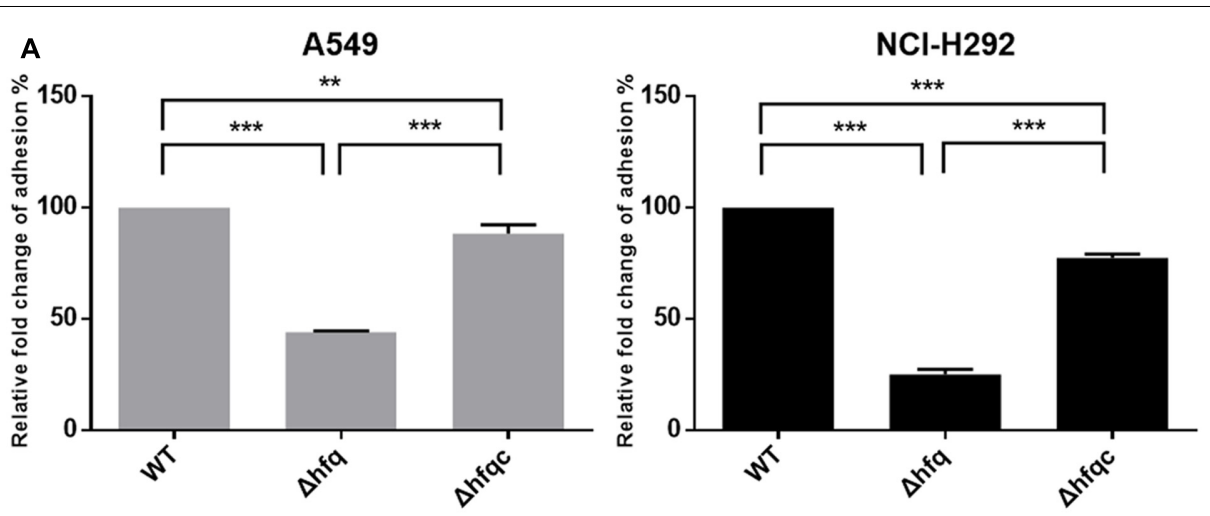

B
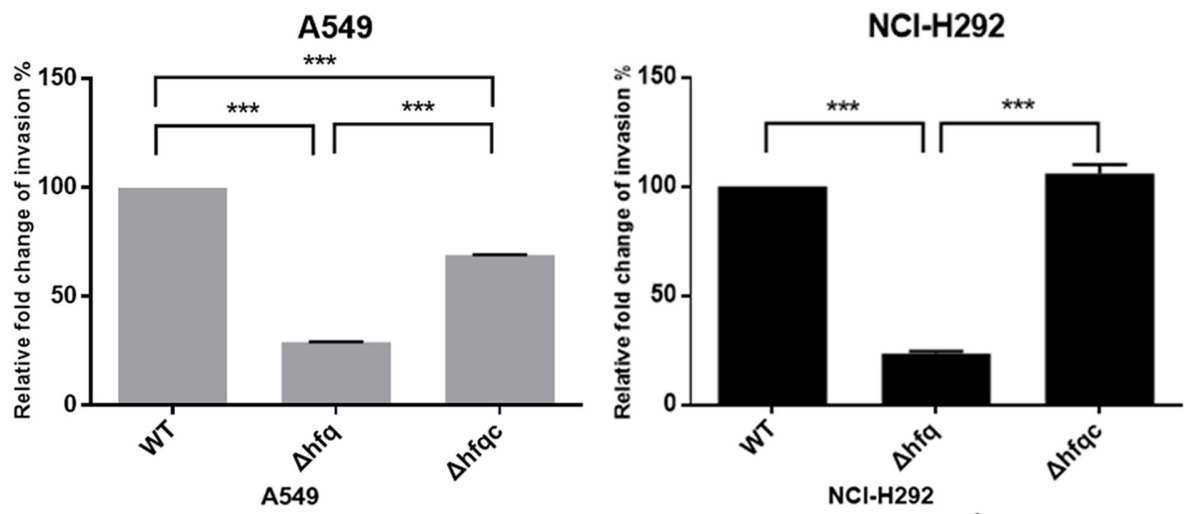

C
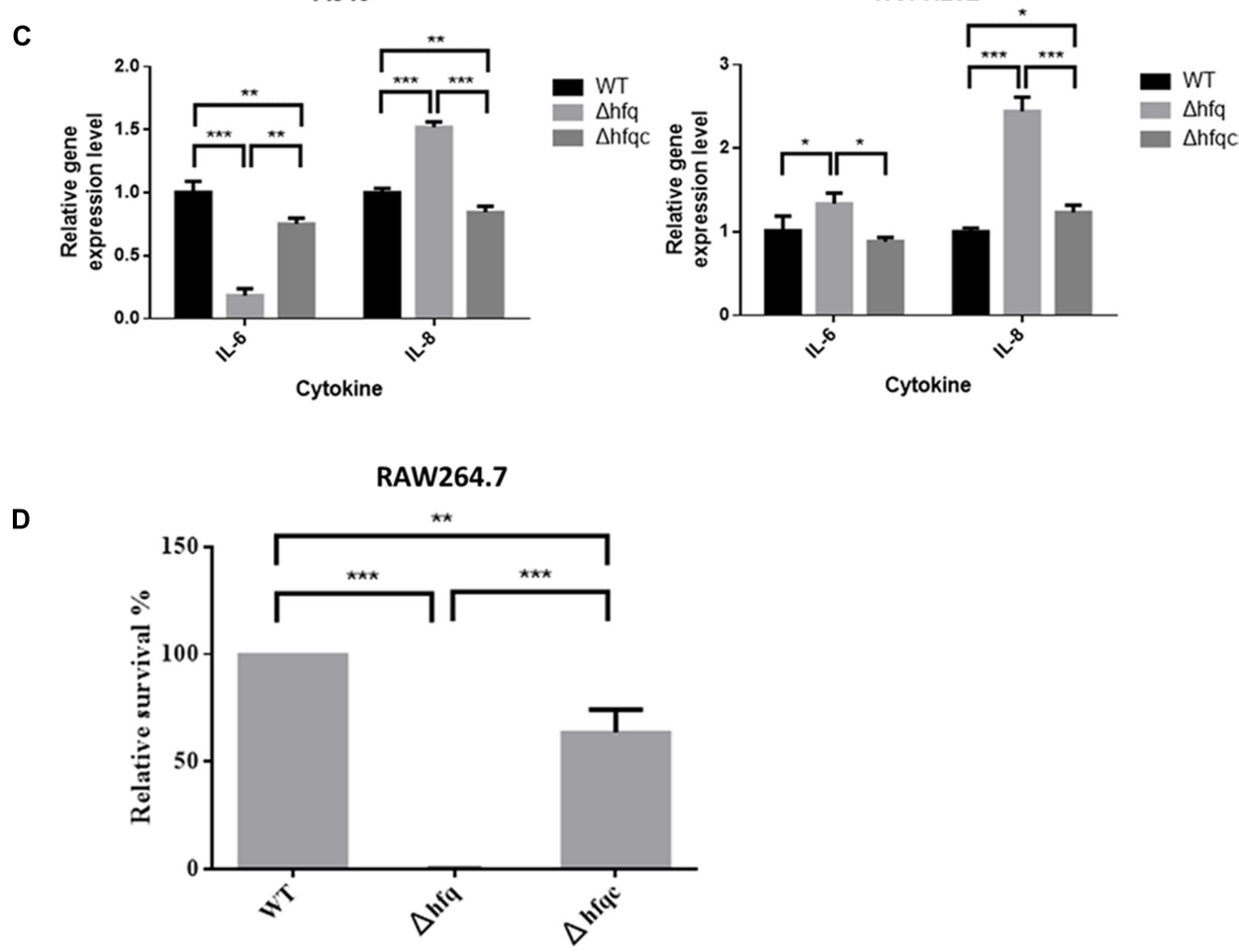

FIGURE 7 | The effect of Hfq on the adhesion, invasion, cytokine secretion of airway epithelial cells and survival in macrophage. (A) Adhesion abilities, (B) invasion abilities, (C) relative mRNA expression of IL-6 and IL-8 as analyzed by real-time RT-PCR, and (D) survival of bacteria in macrophage RAW264.7. The abilities to adhere to and invade A549 and NCl-H292 cells and intra-macrophage survival were determined as described in the Section "Materials and Methods." The adhesion, invasion, and survival abilities of wild-type were set at $100 \%$, and the other data are reported relative to these values. All data represent the average of three independent experiments with the SD. ${ }^{*} p<0.05 ;{ }^{* *} p<0.01 ; * * p<0.001$. 
ability may reflect a gene dosage effect. All the pleiotropic effect could be explained by indirect consequences resulting from the loss of $h f q$.

Alterations of biofilm formation and colony morphology due to deletion of $h f q$ have been demonstrated in several bacteria (Deng et al., 2016). However, reports of the precise visualization of cell morphology such as OMVs and fimbriae upon deletion of $h f q$ remain limited. OMVs are an important vehicle designed to deliver effector molecules such as OmpA to host cells that contribute to pathogenesis during A. baumannii infection (Kwon et al., 2009; Jin et al., 2011). Our study reveals that the total proteins of OMVs are greatly reduced upon loss of the $h f q$ gene. In E. coli, OmpA is downregulated by hfq-binding sRNA (Guillier et al., 2006). Based on our result (Figure 2C), we suggest that Hfq is necessary for OmpA expression.

Bacterial fimbriae have been recognized as mediators of initial host-pathogen interactions important for the progression of Gram-negative bacterial diseases (Kline et al., 2010). In addition, fimbriae have been implicated in other functions, such as phage-binding, DNA transfer, biofilm formation, cell aggregation, host cell invasion, and twitching motility (Proft and Baker, 2009). Several types of fimbriae have been described in A. baumannii (Tomaras et al., 2003; Harding et al., 2013). Type I fimbriae encoded by the CsuA/BABCDE chaperoneusher fimbria assembly system are involved in biofilm formation but are less important for adherence to mammalian cells (de Breij et al., 2009). Type IV fimbriae are involved in natural transformation and twitching motility but not surfaceassociated motility (Harding et al., 2013). In addition to the CsuA/BABCDE chaperone-usher fimbria assembly system, A1S_1507 and A1S_2091 have been found in the pellicle matrix formed by $A$. baumannii at the air-liquid surface (Nait Chabane et al., 2014). Moreover, A1S_1507 is involved in biofilm formation (Rumbo-Feal et al., 2013). Our AFM images revealed that fimbriae were greatly reduced in the $\Delta \mathrm{hfq}$ mutant, implying that $A$. baumannii $\mathrm{Hfq}$ is required for fimbriae production. Moreover, reduction of fimbriae production in the $\Delta$ hfq mutant may reduce biofilm formation and cell adhesion and invasion (Figures 6, 7). Interestingly, we also found that Hfq modulates fimbriae formation in a different manner. We hypothesized that Hfq can simultaneously upregulate and downregulate functionally different fimbriae. In addition, we suggested that the reduction of biofilm formation in $\Delta \mathrm{hfq}$ mutants may be mainly due to the reduction of Csu fimbriae rather than A1S_1507.

The ability of $A$. baumannii to sense and react to environmental and host stress signals allows it to persist and disseminate in medical settings and human hosts. Stressors include iron, an essential micronutrient for almost all living cells and organisms that causes severe damage when not properly controlled, and chemical antiseptics normally used in human medicine (Fiester and Actis, 2013). Acinetobactin, a siderophore from A. baumannii, is critical for acquisition of iron from culture media and from host cells and tissues (Mihara et al., 2004). The acinetobactin gene cluster contains 18 genes divided among 7 operons and includes 10 bas (acinetobactin biosynthesis) genes, 6 bau (acinetobactin utilization) genes and 2 bar (acinetobactin release) genes. Our finding shows that Hfq might be involved in the downregulation of acinetobactin via destabilization of the bauA and basD transcripts. Our results also indicate that Hfq downregulates several stress-related outer membrane proteins (OMPs). NlpE, an outer membrane lipoprotein that activates the Cpx signaling pathway, plays a role in sensing and inducing responses to different stressors (Chao and Vogel, 2016). A1S_0820, a protein containing the LysM domain, participates in the remodeling of the cell wall as cells grow into stationary phase (Soares et al., 2010). CarO is an OMP implicated in antibiotic resistance and ornithine transport (Mussi et al., 2007). The most abundant OMPs, such as OmpC, OmpF, and OmpA, are downregulated by Hfq-binding sRNA in E. coli (Guillier et al., 2006), indicating that sRNA regulation may be important for balancing porin levels or responding to the environment. In addition to OMPs, other stress-related proteins, GroEL and UspA, were also downregulated by Hfq. The association of Hfq and those stress-related proteins remains to be determined. However, our results show that deletion of $h f q$ results in the overexpression of stress-related molecules and hypersensitization to environmental stresses.

Changes in OMPs caused by $h f q$ mutation have been demonstrated to induce cytokine production (Wang et al., 2014), which is important to eliminate bacterial pathogens by triggering inflammatory responses. A. baumannii OMVs may elicit a potent innate immune response via membrane proteins (Jun et al., 2013; Kaparakis-Liaskos and Ferrero, 2015). Although OMVs were greatly reduced in the $\Delta \mathrm{hfq}$ mutant, the over-expression of surface proteins is likely to alter the immunogenicity of this bacterium or virulence factors that stimulates immune response to promote bacterial clearance by the host.

\section{CONCLUSION}

This study implicates Hfq as a pivotal coordinator of diverse regulatory circuits, including cell-surface and/or cellular components. We provide evidence that, similar to its roles in other bacteria, Hfq has pleiotropic effects on stress tolerance, biofilm formation, cell morphology, epithelial cell adhesion, and invasion in A. baumannii. Our study provides a promising start for the characterization of the detailed regulatory mechanisms of Hfq and Hfq-regulated sRNA in the virulence of A. baumannii.

\section{AUTHOR CONTRIBUTIONS}

$\mathrm{H}-\mathrm{YK}, \mathrm{LH}$, and M-LL designed the research project. P-CL, H-HC, K-CC, and C-HT carried out the experiment. M-LL, H-YK, and $\mathrm{C}-\mathrm{HC}$ wrote the manuscript. All authors have read and approved the final manuscript.

\section{FUNDING}

The present work was partially supported by a grant from the Ministry of Science and Technology (grant MOST 
105-2627-M-009-005 and grant MOST 105-2627-M-126-001), and Taiwan University Hospital Hsin-Chu Branch (grant 105$\mathrm{HCH} 011$ and 106-HCH009).

\section{ACKNOWLEDGMENT}

We would like to thank Dr. Wei-En Fu and Dr. Bo-Ching He at the Center for Measurement Standards of Industrial Technology

\section{REFERENCES}

Aranda, J., Poza, M., Pardo, B. G., Rumbo, S., Rumbo, C., Parreira, J. R., et al. (2010). A rapid and simple method for constructing stable mutants of Acinetobacter baumannii. BMC Microbiol. 10:279. doi: 10.1186/1471-218010-279

Baggiolini, M., and Clark-Lewis, I. (1992). Interleukin-8, a chemotactic and inflammatory cytokine. FEBS Lett. 307, 97-101. doi: 10.1016/0014-5793(92) 80909-Z

Bohn, C., Rigoulay, C., and Bouloc, P. (2007). No detectable effect of RNAbinding protein Hfq absence in Staphylococcus aureus. BMC Microbiol. 7:10. doi: 10.1186/1471-2180-7-10

Buist, G., Steen, A., Kok, J., and Kuipers, O. P. (2008). LysM, a widely distributed protein motif for binding to (peptido)glycans. Mol. Microbiol. 68, 838-847. doi: 10.1111/j.1365-2958.2008.06211.x

Chang, K. C., Kuo, H. Y., Tang, C. Y., Chang, C. W., Lu, C. W., Liu, C. C., et al. (2014). Transcriptome profiling in imipenem-selected Acinetobacter baumannii. BMC Genomics 15:815. doi: 10.1186/1471-2164-15-815

Chao, Y., and Vogel, J. (2010). The role of Hfq in bacterial pathogens. Curr. Opin. Microbiol. 13, 24-33. doi: 10.1016/j.mib.2010.01.001

Chao, Y., and Vogel, J. (2016). A 3' UTR-derived small RNA provides the regulatory noncoding arm of the inner membrane stress response. Mol. Cell. 61, 352-363. doi: 10.1016/j.molcel.2015.12.023

Choi, C. H., Lee, J. S., Lee, Y. C., Park, T. I., and Lee, J. C. (2008). Acinetobacter baumannii invades epithelial cells and outer membrane protein A mediates interactions with epithelial cells. BMC Microbiol. 8:216. doi: 10.1186/14712180-8-216

Consales, G., Gramigni, E., Zamidei, L., Bettocchi, D., and De Gaudio, A. R. (2011). A multidrug-resistant Acinetobacter baumannii outbreak in intensive care unit: antimicrobial and organizational strategies. J. Crit. Care 26, 453-459. doi: 10.1016/j.jcrc.2010.12.016

de Breij, A., Gaddy, J., Van Der Meer, J., Koning, R., Koster, A., Van Den Broek, P., et al. (2009). CsuA/BABCDE-dependent pili are not involved in the adherence of Acinetobacter baumannii ATCC19606(T) to human airway epithelial cells and their inflammatory response. Res. Microbiol. 160, 213-218. doi: 10.1016/ j.resmic.2009.01.002

Deng, Y., Chen, C., Zhao, Z., Zhao, J., Jacq, A., Huang, X., et al. (2016). The RNA chaperone $\mathrm{Hfq}$ is involved in colony morphology, nutrient utilization and oxidative and envelope stress response in Vibrio alginolyticus. PLOS ONE 11:e0163689. doi: 10.1371/journal.pone.0163689

Ding, Y., Davis, B. M., and Waldor, M. K. (2004). Hfq is essential for Vibrio cholerae virulence and downregulates sigma expression. Mol. Microbiol. 53, 345-354. doi: 10.1111/j.1365-2958.2004.04142.x

Dorel, C., Lejeune, P., and Rodrigue, A. (2006). The Cpx system of Escherichia coli, a strategic signaling pathway for confronting adverse conditions and for settling biofilm communities? Res. Microbiol. 157, 306-314.

Eijkelkamp, B. A., Hassan, K. A., Paulsen, I. T., and Brown, M. H. (2011). Investigation of the human pathogen Acinetobacter baumannii under iron limiting conditions. BMC Genomics 12:126. doi: 10.1186/1471-2164-12-126

Elhosseiny, N. M., Amin, M. A., Yassin, A. S., and Attia, A. S. (2015). Acinetobacter baumannii universal stress protein A plays a pivotal role in stress response and is essential for pneumonia and sepsis pathogenesis. Int. J. Med. Microbiol. 305, 114-123. doi: 10.1016/j.ijmm.2014.11.008

Fiester, S. E., and Actis, L. A. (2013). Stress responses in the opportunistic pathogen Acinetobacter baumannii. Future Microbiol. 8, 353-365. doi: 10.2217/fmb. 12.150
Research Institute in Taiwan for providing the atomic force microscope and technical support.

\section{SUPPLEMENTARY MATERIAL}

The Supplementary Material for this article can be found online at: https://www.frontiersin.org/articles/10.3389/fmicb. 2017.02068/full\#supplementary-material

Franze de Fernandez, M. T., Eoyang, L., and August, J. T. (1968). Factor fraction required for the synthesis of bacteriophage Qbeta-RNA. Nature 219, 588-590. doi: $10.1038 / 219588 \mathrm{a} 0$

Gaddy, J. A., and Actis, L. A. (2009). Regulation of Acinetobacter baumannii biofilm formation. Future Microbiol. 4, 273-278. doi: 10.2217/fmb.09.5

Gaddy, J. A., Arivett, B. A., Mcconnell, M. J., Lopez-Rojas, R., Pachon, J., and Actis, L. A. (2012). Role of acinetobactin-mediated iron acquisition functions in the interaction of Acinetobacter baumannii strain ATCC $19606^{\mathrm{T}}$ with human lung epithelial cells, Galleria mellonella caterpillars, and mice. Infect. Immun. 80, 1015-1024. doi: 10.1128/IAI.06279-11

Geng, J., Song, Y., Yang, L., Feng, Y., Qiu, Y., Li, G., et al. (2009). Involvement of the post-transcriptional regulator Hfq in Yersinia pestis virulence. PLOS ONE 4:e6213. doi: 10.1371/journal.pone.0006213

Giamarellou, H., Antoniadou, A., and Kanellakopoulou, K. (2008). Acinetobacter baumannii: a universal threat to public health? Int. J. Antimicrob. Agents 32, 106-119. doi: 10.1016/j.ijantimicag.2008.02.013

Giannouli, M., Antunes, L. C., Marchetti, V., Triassi, M., Visca, P., and Zarrilli, R. (2013). Virulence-related traits of epidemic Acinetobacter baumannii strains belonging to the international clonal lineages I-III and to the emerging genotypes ST25 and ST78. BMC Infect. Dis. 13:282. doi: 10.1186/1471-233413-282

Gordon, N. C., and Wareham, D. W. (2010). Multidrug-resistant Acinetobacter baumannii: mechanisms of virulence and resistance. Int. J. Antimicrob. Agents 35, 219-226. doi: 10.1016/j.ijantimicag.2009.10.024

Guillier, M., Gottesman, S., and Storz, G. (2006). Modulating the outer membrane with small RNAs. Genes Dev. 20, 2338-2348. doi: 10.1101/gad.1457506

Harding, C. M., Tracy, E. N., Carruthers, M. D., Rather, P. N., Actis, L. A., Munson, R. S. Jr., et al. (2013). Acinetobacter baumannii strain M2 produces type IV pili which play a role in natural transformation and twitching motility but not surface-associated motility. mBio 4:e00360-13. doi: 10.1128/mBio. 00360-13

Jin, J. S., Kwon, S. O., Moon, D. C., Gurung, M., Lee, J. H., Kim, S. I., et al. (2011). Acinetobacter baumannii secretes cytotoxic outer membrane protein A via outer membrane vesicles. PLOS ONE 6:e17027. doi: 10.1371/journal.pone. 0017027

Jun, S. H., Lee, J. H., Kim, B. R., Kim, S. I., Park, T. I., Lee, J. C., et al. (2013). Acinetobacter baumannii outer membrane vesicles elicit a potent innate immune response via membrane proteins. PLOS ONE 8:e71751. doi: 10.1371/ journal.pone.0071751

Kaparakis-Liaskos, M., and Ferrero, R. L. (2015). Immune modulation by bacterial outer membrane vesicles. Nat. Rev. Immunol. 15, 375-387. doi: 10.1038/nri3837

Kim, S., Hwang, H., Kim, K. P., Yoon, H., Kang, D. H., and Ryu, S. (2015). Hfq plays important roles in virulence and stress adaptation in Cronobacter sakazakii ATCC 29544. Infect. Immun. 83, 2089-2098. doi: 10.1128/IAI.03161-14

Kline, K. A., Dodson, K. W., Caparon, M. G., and Hultgren, S. J. (2010). A tale of two pili: assembly and function of pili in bacteria. Trends Microbiol. 18, 224-232. doi: 10.1016/j.tim.2010.03.002

Kulesus, R. R., Diaz-Perez, K., Slechta, E. S., Eto, D. S., and Mulvey, M. A. (2008). Impact of the RNA chaperone $\mathrm{Hfq}$ on the fitness and virulence potential of uropathogenic Escherichia coli. Infect. Immun. 76, 3019-3026. doi: 10.1128/IAI. 00022-08

Kwon, S. O., Gho, Y. S., Lee, J. C., and Kim, S. I. (2009). Proteome analysis of outer membrane vesicles from a clinical Acinetobacter baumannii isolate. FEMS Microbiol. Lett. 297, 150-156. doi: 10.1111/j.1574-6968.2009.01669.x

Lee, H. W., Koh, Y. M., Kim, J., Lee, J. C., Lee, Y. C., Seol, S. Y., et al. (2008). Capacity of multidrug-resistant clinical isolates of Acinetobacter baumannii to 
form biofilm and adhere to epithelial cell surfaces. Clin. Microbiol. Infect. 14, 49-54. doi: 10.1111/j.1469-0691.2007.01842.x

Lee, J. C., Koerten, H., Van Den Broek, P., Beekhuizen, H., Wolterbeek, R., Van Den Barselaar, M., et al. (2006). Adherence of Acinetobacter baumannii strains to human bronchial epithelial cells. Res. Microbiol. 157, 360-366. doi: 10.1016/ j.resmic.2005.09.011

Lin, M. F., Lin, Y. Y., Yeh, H. W., and Lan, C. Y. (2014). Role of the BaeSR two-component system in the regulation of Acinetobacter baumannii adeAB genes and its correlation with tigecycline susceptibility. BMC Microbiol. 14:119. doi: 10.1186/1471-2180-14-119

Maragakis, L. L., and Perl, T. M. (2008). Acinetobacter baumannii: epidemiology, antimicrobial resistance, and treatment options. Clin. Infect. Dis. 46, 1254-1263. doi: $10.1086 / 529198$

Mihara, K., Tanabe, T., Yamakawa, Y., Funahashi, T., Nakao, H., Narimatsu, S., et al. (2004). Identification and transcriptional organization of a gene cluster involved in biosynthesis and transport of acinetobactin, a siderophore produced by Acinetobacter baumannii ATCC 19606T. Microbiology 150, 2587-2597. doi: 10.1099/mic.0.27141-0

Moller, T., Franch, T., Hojrup, P., Keene, D. R., Bachinger, H. P., Brennan, R. G., et al. (2002). Hfq: a bacterial Sm-like protein that mediates RNA-RNA interaction. Mol. Cell 9, 23-30. doi: 10.1016/S1097-2765(01)00436-1

Mussi, M. A., Relling, V. M., Limansky, A. S., and Viale, A. M. (2007). CarO, an Acinetobacter baumannii outer membrane protein involved in carbapenem resistance, is essential for L-ornithine uptake. FEBS Lett. 581, 5573-5578. doi: 10.1016/j.febslet.2007.10.063

Nait Chabane, Y., Marti, S., Rihouey, C., Alexandre, S., Hardouin, J., Lesouhaitier, O., et al. (2014). Characterisation of pellicles formed by Acinetobacter baumannii at the air-liquid interface. PLOS ONE 9:e111660. doi: 10.1371/journal.pone. 0111660

Oglesby, I. K., Vencken, S. F., Agrawal, R., Gaughan, K., Molloy, K., Higgins, G., et al. (2015). miR-17 overexpression in cystic fibrosis airway epithelial cells decreases interleukin-8 production. Eur. Respir. J. 46, 1350-1360. doi: 10.1183/ 09031936.00163414

Proft, T., and Baker, E. N. (2009). Pili in Gram-negative and Gram-positive bacteria - structure, assembly and their role in disease. Cell Mol. Life Sci. 66, 613-635. doi: 10.1007/s00018-008-8477-4

Rosen, G., Naor, R., Rahamim, E., Yishai, R., and Sela, M. N. (1995). Proteases of Treponema denticola outer sheath and extracellular vesicles. Infect. Immun. 63, 3973-3979.

Rumbo-Feal, S., Gomez, M. J., Gayoso, C., Alvarez-Fraga, L., Cabral, M. P., Aransay, A. M., et al. (2013). Whole transcriptome analysis of Acinetobacter baumannii assessed by RNA-sequencing reveals different mRNA expression profiles in biofilm compared to planktonic cells. PLOS ONE 8:e72968. doi: 10.1371/journal.pone.0072968

Sauter, C., Basquin, J., and Suck, D. (2003). Sm-like proteins in Eubacteria: the crystal structure of the Hfq protein from Escherichia coli. Nucleic Acids Res. 31, 4091-4098. doi: 10.1093/nar/gkg480

Scheller, J., Chalaris, A., Schmidt-Arras, D., and Rose-John, S. (2011). The pro- and anti-inflammatory properties of the cytokine interleukin-6. Biochim. Biophys. Acta 1813, 878-888. doi: 10.1016/j.bbamcr.2011.01.034

Schiano, C. A., Bellows, L. E., and Lathem, W. W. (2010). The small RNA chaperone $\mathrm{Hfq}$ is required for the virulence of Yersinia pseudotuberculosis. Infect. Immun. 78, 2034-2044. doi: 10.1128/IAI.01046-09

Schilling, D., and Gerischer, U. (2009). The Acinetobacter baylyi Hfq gene encodes a large protein with an unusual C terminus. J. Bacteriol. 191, 5553-5562. doi: 10.1128/JB.00490-09

Simonsen, K. T., Nielsen, G., Bjerrum, J. V., Kruse, T., Kallipolitis, B. H., and Moller-Jensen, J. (2011). A role for the RNA chaperone Hfq in controlling adherent-invasive Escherichia coli colonization and virulence. PLOS ONE 6:e16387. doi: 10.1371/journal.pone.0016387

Sittka, A., Pfeiffer, V., Tedin, K., and Vogel, J. (2007). The RNA chaperone Hfq is essential for the virulence of Salmonella typhimurium. Mol. Microbiol. 63, 193-217. doi: 10.1111/j.1365-2958.2006.05489.x

Smith, M. G., Gianoulis, T. A., Pukatzki, S., Mekalanos, J. J., Ornston, L. N., Gerstein, M., et al. (2007). New insights into Acinetobacter baumannii pathogenesis revealed by high-density pyrosequencing and transposon mutagenesis. Genes Dev. 21, 601-614. doi: 10.1101/gad.1510307

Soares, N. C., Cabral, M. P., Gayoso, C., Mallo, S., Rodriguez-Velo, P., FernandezMoreira, E., et al. (2010). Associating growth-phase-related changes in the proteome of Acinetobacter baumannii with increased resistance to oxidative stress. J. Proteome Res. 9, 1951-1964. doi: 10.1021/pr901116r

Sonnleitner, E., Hagens, S., Rosenau, F., Wilhelm, S., Habel, A., Jager, K. E., et al. (2003). Reduced virulence of a $h f q$ mutant of Pseudomonas aeruginosa O1. Microb. Pathog. 35, 217-228. doi: 10.1016/S0882-4010(03) 00149-9

Storz, G., Vogel, J., and Wassarman, K. M. (2011). Regulation by small RNAs in bacteria: expanding frontiers. Mol. Cell 43, 880-891. doi: 10.1016/j.molcel.2011. 08.022

Tang, C. Y., Yiu, S. M., Kuo, H. Y., Tan, T. S., Liao, K. H., Liu, C. C., et al. (2015). Application of $16 \mathrm{~S}$ rRNA metagenomics to analyze bacterial communities at a respiratory care centre in Taiwan. Appl. Microbiol. Biotechnol. 99, 2871-2881. doi: 10.1007/s00253-014-6176-7

Tomaras, A. P., Dorsey, C. W., Edelmann, R. E., and Actis, L. A. (2003). Attachment to and biofilm formation on abiotic surfaces by Acinetobacter baumannii: involvement of a novel chaperone-usher pili assembly system. Microbiology 149 , 3473-3484. doi: 10.1099/mic.0.26541-0

Vallenet, D., Nordmann, P., Barbe, V., Poirel, L., Mangenot, S., Bataille, E., et al. (2008). Comparative analysis of Acinetobacters: three genomes for three lifestyles. PLOS ONE 3:e1805. doi: 10.1371/journal.pone.0001805

Vecerek, B., Rajkowitsch, L., Sonnleitner, E., Schroeder, R., and Blasi, U. (2008). The C-terminal domain of Escherichia coli $\mathrm{Hfq}$ is required for regulation. Nucleic Acids Res. 36, 133-143. doi: 10.1093/nar/gkm985

Vogel, J., and Luisi, B. F. (2011). Hfq and its constellation of RNA. Nat. Rev. Microbiol. 9, 578-589. doi: 10.1038/nrmicro2615

Wang, M. C., Chien, H. F., Tsai, Y. L., Liu, M. C., and Liaw, S. J. (2014). The RNA chaperone Hfq is involved in stress tolerance and virulence in uropathogenic Proteus mirabilis. PLOS ONE 9:e85626. doi: 10.1371/journal.pone. 0085626

Waters, L. S., and Storz, G. (2009). Regulatory RNAs in bacteria. Cell 136, 615-628. doi: 10.1016/j.cell.2009.01.043

Zimbler, D. L., Penwell, W. F., Gaddy, J. A., Menke, S. M., Tomaras, A. P., Connerly, P. L., et al. (2009). Iron acquisition functions expressed by the human pathogen Acinetobacter baumannii. Biometals 22, 23-32. doi: 10.1007/s10534-0089202-3

Conflict of Interest Statement: The authors declare that the research was conducted in the absence of any commercial or financial relationships that could be construed as a potential conflict of interest.

Copyright (c) 2017 Kuo, Chao, Liao, Hsu, Chang, Tung, Chen and Liou. This is an open-access article distributed under the terms of the Creative Commons Attribution License (CC BY). The use, distribution or reproduction in other forums is permitted, provided the original author(s) or licensor are credited and that the original publication in this journal is cited, in accordance with accepted academic practice. No use, distribution or reproduction is permitted which does not comply with these terms. 